\title{
The complete list of scientific publications of Prof. Árpád Berczik
}

\author{
M. DINKA
}

Mária Dinka, 2600 Vác, Rácz Pál.str. 3. E-mail: dinka.maria@outlook.hu

\begin{abstract}
Berczik the renowned hydrobilogist celebrated his 88th birthday in this year. His research covered systematics, ecology and larval abundance of the Chironomidae, paying attention to the nutrient cycle of the shallow lakes, which is a characteristic of Hungary. He is a member of the Hungarian Academy of Sciences since 1982 and author of some 158 research publication listed below.
\end{abstract}

\begin{abstract}
Á rpád Berczik (born in 1929, Budapest) gained A his qualifications in Biology and Geography graduating from the Eötvös Loránd University (Budapest). He primarily did hydrobiological studies, which he later further scrutinized mainly in Austria (Wienna, Lunz/See), Germany (Plön/ Holstein), France (Toulouse), Switzerland (Dübendorf) and Poland (Olsztyn, Mikolajki). Since 1952 he has been a researcher of the HAS, and since 1973 an associate professor at the former university, then a university professor. He has been a member of the HAS since 1982. His research covered the systematics, ecology, larval abundance of the Chironomidae, paying attention to the nutrient cycle of the shallow lakes, which is a characteristic of Hungary.
\end{abstract}

His investigations extended to the Chironomidae assemblages of the extremely shallow rice fields he also revealed a pest species. - He also participated in the research of the thermal waters and intermittent sodic lakes. He made a significant contribution to the hydrobiological exploration of Lake Fertö/Neusiedler See. From the beginning he has been involved in the organization and implementation of the organized and regular, extensive hydro-ecological, and biological research of the River Danube, which started in 1957. In this issue he put particular emphasis on the importance of the cooperation with the co-sciences (like hydrology, climatology, water management, nature protection, etc.). He tried to enforce his views as a participant of the Hunga rian Danube Hydrobiological Research, then as its leader for decades and as an institute director and professor. He established significant international relationships and gained recognition for the Chironomidae research, then for his hydroecological research of shallow lakes and rivers. His work was recognized by higher state and national scientific awards and honours. In recent years he has been arranging the documents of his multifaceted scientific activity, science policy, and teaching work.

\section{LIST OF PUBLICATIONS}

1956

1. BERCZIK, Á. (1956): Újabb hidrobiológiai vizsgálatok a Lukács-gyógyfürdő Malom-taván. Állattani Közlemények, 45: 35-44.

2. BERCZIK, Á. (1956): Quelques espèces de Chironomides nouvelles pour la faune de la Hongrie. Opuscula Zoologica (Budapest), 1: 19-24.

3. BERCZIK, Á. (1956): Mennyiségi és minöségi vizsgálatok iszaplakó Chironomida lárvákon. Kandidátusi értekezés, Budapest, p. 177.

1957

4. BERCZIK, Á. (1957): Polypedilum Dudichi sp. n., eine neue Art der Familie Chironomidae. Opuscula Zoologica (Budapest), 2: 15-20.

5. BERCZIK, Á. (1957): Chironomidák, és a tótipustan néhány hazai kérdése. Állattani Közlemények, 46: 33-41. 
6. BERCZIK, Á. (1957): Trichocladius bicinctus $\mathrm{Mg}$. comme mineur nuisible des feuilles du riz. Opuscula Zoologica (Budapest), 2: 21-23.

7. BERCZIK, Á. (1957): Funde von Chironomidenlarven aus einem Reisfelde. Annales Universitatis Scientiarum Budapestinensis de Rolando Eötvös Nominatae. Sectio biologica, 1: 13-16.

\section{8}

8. BERCZIK, Á. (1958): Einige neue Angaben über die Parasiten der Chironomidenlarven. Opuscula Zoologica (Budapest), 2: 13-17.

1959

9. BERCZIK, Á. (1959): Beitrag zur Kenntnis der Chironomidenfauna des toten Theissarmes bei Szajol (Ungarn). Opuscula Zoologica (Budapest), 3: 19-22.

10. BERCZIK, Á. (1959): Chironomidenlarven aus dem Gebiete des Gran Flusses (Tschechoslowakei). Annales Universitatis Scientiarum Budapestinensis de Rolando Eötvös Nominatae. Sectio biologica, 2: 43-48.

\section{0}

11. BERCZIK, Á. (1960): Ein bemerkenswerter Fund der Larve von Euphaenocladius aquatilis Goetgh. (Chironomidae) aus Ungarn. Opuscula Zoologica (Budapest), 4: 15-17.

12. BERCZIK, Á. (1960): Faunistische Übersicht der bis jetzt bekannten Chironomiden des BalatonSees. Annales Universitatis Scientiarum Budapestinensis de Rolando Eötvös Nominatae. Sectio biologica, 3: 69-73.

13. BERCZIK, Á. (1960): Egy sajátos földalatti élőhely állatvilágáról. Hidrológiai Közlöny, 40: 516-518.

1961

14. BERCZIK, Á. (1961): Einige Beobachtungen bezüglich der horizontalen Verteilung des Makrobenthos seichter "pannonischer" Seen. Acta Zoologica Academiae Scientiarum Hungaricae, 7: 49-72.

15. BERCZIK, Á. (1961): Nemzetközi összefogás a Duna biológiai kutatására. Hidrológiai Tájékoztató, 1(2): 45.

1962

16. BERCZIK, Á. (1962): Kénhidrogénszint és a hazai eutróf tavak benthosának produkciója. Állattani Közlemények, 49: 35-39.
17. BERCZIK, Á. (1962): Die Winter-Chironomidenfauna eines Tränktroges. Opuscula Zoologica (Budapest), 4: 63-65.

1964

18. BERCZIK, Á. (1964): Angaben über das Vorkommen von Chironomidenlarven lauwarmer Gewässer. Opuscula Zoologica (Budapest), 5: 43-47.

\section{5}

19. BERCZIK, Á. (1965): A vízjárás hatása a magyar Duna-szakasz állatvilágára. Hidrológiai Közlöny, 45: 233-236.

20. BERCZIK, Á. (1965): Die Chironomidenlarven aus dem Periphyton der Landungsmolen in Donauabschnitt zwischen Budapest und Mohács. Acta Zoologica Academiae Scientiarum Hungaricae, 9: 227-236.

21. BerczIK, Á. (1965): Prof. Dr. Umberto d'Ancona 1896-1964. Hidrológiai Közlöny, 45: 308.

22. BERCZIK, Á. \& HorÁNSZKY, A. (1965): A Duna növény- és állatvilága. In. PAPP, M. (Ed.) Duna-utikönyv, Panoráma, Budapest, p. 30-39.

\section{6}

23. BERCZIK, Á. (1966): Chironomidenlarven aus dem Aufwuchs der Schwimmkörper im Donauabschnitt zwischen Rajka und Budapest Acta Zoologica Academiae Scientiarum Hungaricae, 12: 41-51.

24. BERCZIK, Á. (1966): Über den Einfluss einiger hydrologischen Faktoren auf die Besiedlungsmöglichkeiten der Fauna der Mittleren-Donau. Annales Universitatis Scientiarum Budapestinensis de Rolando Eötvös Nominatae. Sectio biologica, 8: 25-32.

25. BERCZIK, Á. (1966): Chironomidenforschung in Ungarn. Gewässer und Abwässer, 41/42: 136-144.

26. BERCZIK, Á. (1966): Über die Wasserfauna in Anland des ungarischen Donauabschnittes. Danubialia Hungarica. XXXV. Opuscula Zoologica (Budapest), 6: 79-91.

27. BERCZIK, Á. (1966): Zur Populationsdynamik des Zoobenthos eines seichten Sees. Acta Zoologica Academiae Scientiarum Hungaricae, 12: 235-249.

28. BERCZIK, Á. (1966): Chironomida-kutatás rendszertani problémáiról. Állattani Közlemények, 53: 43-47. 
29. BERCZIK, Á. (1966): Dr. Dudich Endre az MTA rendes tagja. Hidrológiai Közlöny, 46: 221.

\section{7}

30. BERCZIK, Á. (1967): Chironomiden-larven und Puppen aus dem Hámori-See. Acta Zoologica Academiae Scientiarum Hungaricae, 13: 75-82.

31. BERCZIK, Á. (1967): Hidrobiológia a hazai felsőoktatásban. Hidrológiai Tájékoztató, 1967 (11): 87-88.

32. BERCZIK, Á. (1967): Zur Populationsdynamik des Makrobenthos in Velencer See. Opuscula Zoologica (Budapest), 6: 247-265.

33. BERCZIK, Á. (1967): Benthos-Chironomiden des Mosoner Donau-armes. Opuscula Zoologica (Budapest), 7: 45-54.

34. BERCZIK, Á. (1967): Vorkommen einiger Chironomiden aus zwei Natrongewässer. Opuscula Zoologica (Budapest), 7: 75-82.

35. BercziK, Á., KozMA, E., Molnár, M. (1967): Hidrobiológiai vizsgálatok a Hámori-tavon. Hidrológiai Közlöny, 47: 79-89.

1968

36. BERCZIK, Á. (1968): Zur Kenntnis der bachbewohnenden Chironomiden Ungarns. Acta Zoologica Academiae Scientiarum Hungaricae, 14: 15-25.

37. BERCZIK, Á. (1968): Über die Chironomiden eines Moosaufwuchses in Nordungarn. Annales Zoologici Fennici, 5: 17-21.

38. BERCZIK, Á. (1968): Chironomidenlarven aus einer nordungarischen Tropfsteinhöhle. Opuscula Zoologica (Budapest), 8: 347-350.

39. BERCZIK, Á. (1968): Limnológiai Szakosztály az 50 éves Magyar Hidrológiai Társaságban. Hidrológiai Tájékoztató, 1968(06): 15-16.

40. BercziK, Á., KozMA, E., Molnár, M. (1968): Hydrobiologische Untersuchungen am ältesten Stausee Ungarns. Annales Universitatis Scientiarum Budapestinensis de Rolando Eötvös Nominatae. Sectio biologica, 9/10: 37-64.

41. Kozma, E.V., Molnár, M. \& BercziK, Á. (1968): Veränderungen der Umweltsbedingungen und der Bodenfauna eines fischereilich bewirtschafteten seichten Sees. Opuscula Zoologica (Budapest), 8: 37-55.
1969

42. BERCZIK, Á. (1969): Über die Chironomiden im Benthal des ungarischen Donauabschnittes. Acta Zoologica Academiae Scientiarum Hungaricae, 5: 277-285.

43. BERCZIK, Á. (1969): Die Chironomiden in der Uferregion des ungarischen Donauabschnittes. Opuscula Zoologica (Budapest), 9: 249-254.

\section{0}

44. Pusztai, Gy., BercziK, Á. \& VÉGH, S-NÉ. (1970): A Fövárosi Vizmüvek talajvízdúsitásának kutatási eredményei és problémái. MHT II. Vízminőségi és Víztechnológiai Kongresszus Kiadványa Budapest, p. 1-23.

1971

45. BERCZIK, Á. (1971): Die Chironomiden und ihre Lebensstätten auf dem ungarischen Donauabschnitt. Limnologica (Berlin), 8: 61-71.

46. BERCZIK, Á. (1971): Schädigung eines Reisfeldes durch Chironomiden und seine ökologischen Umstände. Opuscula Zoologica (Budapest), 10: 221-230.

47. BERCZIK, Á. (1971): Dr. Olga Sebestyén is 80 . Annales Instituti Biologici (Tihany) Hungaricae Academiae Scientiarum, 38: 3-10.

48. BERCZIK, Á. (1971): Dr. Dudich Endre 1895-1971. Hidrológiai Közlöny, 51: 343-344.

1972

49. BERCZIK, Á. (1972): Hidrobiológia, zoológia. In. PICHLER J. (Ed.) A Fertő-tájjal kapcsolatos kutatásokat és feltárásokat áttekintő helyzetfelmérő tanulmányok. 5. (A táj bioszférája.), MTA Fertő-táj Bizottság, Budapest, p. 72-84.

50. BERCZIK, Á. (1972): Zur Populationsdynamik der Mesofauna der Reissfelder. Sitzungsberichte der Akademie der Wissenschaften mathematisch-naturwissenschaftliche Klasse, 179(5-10): 299-302.

1973

51. BERCZIK, Á. (1973): Benennung der zwei ökologischen Gruppen wasserbewohnender Wirbellosen. Opuscula Zoologica (Budapest), 12: $33-41$.

52. BERCZIK, Á. (Ed.) (1973): A magyar hidrobiológiai kutatás helyzete és feladatai. MTA 
Biológiai Tudományok Osztályának közleményei, 16: 319-332.

53. BERCZIK, Á. (1973): A hidrobiológiai kutatások helyzete és feladatai Magyarországon. Állattani Közlemények, 60: 55-65.

54. BERCZIK, Á. (1973): Periodische Aspektenveränderungen der Zoozönosen auf Reisfeldern in Ungarn. Verhandlungen des Internationalen Verein Limnologie, 18: 1742-1750.

55. BERCZIK, Á. (1973): Prof. Dr. Endre Dudich. Opuscula Zoologica (Budapest), 11: 3-5.

1974

56. BERCZIK, Á. (1974): Az asztatikus vizek egy típusa. (Limnológiai tanulmány rizsföldeken). MTA doktori értekezés, Tézisek, p. 1-18.

57. BERCZIK, Á.(1974): Az asztatikus vizek egy típusa. (Limnológiai tanulmány rizsföldeken). MTA doktori értekezés, pp. 310.

\section{5}

58. BERCZIK, Á. (1975): Gesichtspunkte und neuere Ergebnisse in der Erforschung des Donaubenthos. 18. Arbeitstagung der IAD Regensburg/Deutschland, Übersichtreferate 3, p. 47-68.

59. ANDrikOVICS, S. \& BERCZIK, Á. (1975): Hidrobiológia, zoológia. In. AUJESZKY, L., SCHILLING, F. \& SomogYI, S. (Ed.) A Fertő-táj Monográfiáját előkészítő adatgyüjtemény 3, Budapest, p. 423-537.

1977

60. BERCZIK, Á. (1977): Untersuchung der Frassintensität der reisblattminierenden Chironomiden. Opuscula Zoologica (Budapest), 13: 31-35.

61. BERCZIK, Á. (1977): Beobachtungen über die Abundanz von Chironomidenlarven in junger Reissaat. Opuscula Zoologica (Budapest), 14: 51-54.

62. BERCZIK, Á. (1977): A hidrobiológia és mai feladatai. MTA Biológiai Tudományok Osztályának közleményei, 20: 439-445.

63. BERCZIK, Á. (1977): Dr. Vitális Sándor, 1900-1976. Hidrológiai Közlöny, 57: 57-58.

1978

64. BERCZIK, Á. (1978): Über das Donaubenthos und seine Veränderungen durch menschliche
Eingriffe. 18. Arbeitstagung der IAD Regensburg/Deutschland, Vorträge, p. 47-61.

65. BERCZIK, Á. (1978): Die tierischen Reisschädlinge in Ungarn und zur Frage ihrer Bekämpfung. Opuscula Zoologica (Budapest), 15: 61-73.

1979

66. BERCZIK, Á. (1979): A Fertö-táj biológiai kutatásának terve. In. PICHLER, J. (Ed.) A Fertő-táj tudományos kutatási terve, Budapest, p. 55-60.

67. BERCZIK, Á. (1979): A Fertö-táj zoológiai kutatási témajavaslata. In. PICHLER J. (Ed.) A Fertő-táj tudományos kutatási terve, Budapest, p. 71-72.

68. BERCZIK, Á. (1979): A Fertö-táj hidrobiológiai kutatási témajavaslata. In. PICHLER, J. (Ed.) A Fertő-táj tudományos kutatási terve, Budapest, p. 73-75.

69. BERCZIK, Á. (1979): Geplante biologische Forschungen in der Neusiedlersee-Landschaft. In. PICHLER, J. (Ed.) A Fertő-táj tudományos kutatási terve, Budapest, p. 333-338.

70. BERCZIK, Á. (1979): Einige Probleme der limnologischen Erforschung unserer Fliessgewässer. Schriften des Vereins zur Verbreitung naturwissenschaftlicher Kenntnisse Wien, 117/ 118: 29-40.

71. BERCZIK, Á. (1979): Über die Wechselwirkungen im Bereich des ungarischen Donauabschnittes. 21. Arbeitstagung der IAD Novi Sad/Yugoslavia, p. 79-88.

72. BERCZIK, Á. \& BORHIDI, A. (1979): A budapesti agglomeráció környezetfejlesztésének ökológiai problémái és környezetbiológiai fejlesztési terve. MTA Biológiai Tudományok Osztályának közleményei, 22: 367-390.

1981

73. BERCZIK, Á. (1981): MAB 5 Project. Survey of 10 years activity in Hungary. In. STEFANOVITS, P. (Ed.) MAB Programme. Survey of 10 years activity in Hungary. Hungarian National MAB Committee, Budapest, p. 157-165.

74. BERCZIK, Á. (1981): Ungarn. In. 25 Jahre Internationale Arbeitsgemeinschaft Donauforschung. IAD Wien/Austria, p. 41-46. 
75. BERCZIK, Á. \& MÁTÉ, F. (1981): Isszledovániya antropogenih vlijanniy na vengerszkie vodije ekoszisztemi (Balaton, Dunaj). SZOCMAB III. Congress, Budapest, p. 1-7.

1982

76. BERCZIK, Á. (1982): Az MTA 30 éves Botanikai Kutatóintézete és a 25 éves Magyar Dunakutató Állomás. MTA Biológiai Tudományok Osztályának közleményei, 25: 407-413.

77. BERCZIK, Á. (1982): Kötelezettségeink és törekvéseink az ökológia szolgálatában. MTA Biológiai Tudományok Osztályának közleményei, 25: 459-461.

78. BERCZIK, Á. \& LÖFFLER, H. (1982): Crossing National Boundaries: Europe's First International Biosphere Reserve. IUCN Bulletin, 13(7-9): 67.

1983

79. BERCZIK, Á. (1983): A Duna zoológiai vizsgálatának néhány tanulsága. Állattani Közlemények, 69: 1-5.

1984

80. BERCZIK, Á. (1984): Adaptility of Monitoring Systems in the Management of Biosphere Reserves in Hungary. Conservation, science and society. II. UNESCO - UNEP (Paris), p. 384-388.

81. BERCZIK, Á. (1984): A Pilis Bioszféra Rezervátum kutatási programja. Állattani Közlemények, 71: 13-16.

1986

82. KVĚT,J. \& BERCZIK, Á.(1986): Research projekt on conservation science and evology within biosphere research. UNESCO MAB Programme. Proceedings: European MAB Conference on Biosphere Reserves and Ecological Monitoring, České Budějovice, p. 266-268.

\section{8}

83. BercziK, Á. \& PhAm Ngoc, L. (1988): Hydrobiologische Zustandsänderung während eines Jahrzehntes in einem Mittelgebirgsbach in Ungarn. Opuscula Zoologica (Budapest), 23: 117-132.
1990

84. BERCZIK, Á. (1990): Aquatischer Biotopschutz Neusiedler See. Internationalen Symposiums "Schutz und Entwicklung grosser mitteleuropäischer Binnenseenlandschaften, Bodensee-Neusiedler See-Balaton". Tagungsband, Eisenstadt, p. 99-101.

85. BERCZIK, Á. (1990): Begrüssungsworte des Tagungspräsidenten. Wissenschaftliche Hauptreferat. 24. Arbeitstagung der IAD Szentendre/Ungarn, Budapest. p. 7-8.

1991

86. BERCZIK, Á. (1991): Structure and function of aquatic communities, energy and nutrient cycling in the Danube. In. LÁZÁR, G. (Ed.) Advances in Biological Research in Hungary, 1986-1990, (Ecology). MTA Szegedi Biológiai Központ, p. 52-55.

87. BERCZIK, Á. \& PHAM NGOC, L. (1991): Umweltbedingungen und Makrofauna in einem Flachlandbach Ungarns. Opuscula Zoologica (Budapest), 24: 69-87.

1992

88. DinkA, M. \& BERCZIK, Á. (1992): Über die mosaikartigen Unterschiede der "Inneren Seen" im Neusiedlersee/Fertő. Opuscula Zoologica (Budapest), 25: 51-60.

\section{3}

89. BERCZIK, Á. (1993): Beobachtungen über die Temperaturverhältnisse der oberen Sedimentschichten im Neusiedler See. Biologisches Forschungsinstitut für Burgenland-Bericht, 79: 41-46.

90. BERCZIK, Á. (1993): About the thermic conditions in sediment-water zone of shallow lakes in Hungary. Opuscula Zoologica (Budapest), 26: 53-60.

91. BERCZIK, Á. \& DinKA, M. (1993): Towards the limnological elucidation of the Neusiedlersee/Lake Fertö. $5^{\text {th }}$ International Conference on the Conservation and Management of Lakes, Stresa/Italy, p. 38-42.

92. LÁNG, I. \& BERCZIK, Á. (1993): Beszámoló az EuroMAB IV. Konferenciáról (Zakopane, 1993. 
szeptember 6-8.) NHP/OHP Hiradó, Magyar Nemzeti Bizottságának tájékoztatója, 1993(4): 5-6.

93. LÁNG, I., BANCZEROWSKI, J. \& BERCZIK, Á. (Eds.) (1993): Szigetköz. Környezettudományi kutatások, környezeti állapot, ökológiai követelmények. MTA Budapest, 145 pp.

\section{4}

94. BerCZIK, Á. (1994): Ungarn. In. BloesCh, J. (Ed.) Gesamtbericht der Internationalen Arbeitsgemeinschaft Donauforschung über die wissenschaftliche Tätigkeit in den einzelnen Donauländern. Wien, p. 1-16.

95. BERCZIK, Á. (1994): Zur Problematik der Durchgängigkeit aufgrund der Erfahrungen am Wasserstufensystem Gabcikovo-Nagymaros. In. Lebensraum Donau-Europäisches Ökosystem. Beiträge der Akademie für Natur- und Umweltschutz Baden-Württemberg, Germany, 17: 180-186.

96. BERCZIK, Á. (1994): Über die hydrobiologischen Folgen der veränderten hydrologischen Verhältnisse der kleinen Schüttinsel. 3. Arbeitstagung, Erdwissenschaftliche Aspekte des Umweltschutzes Wien, Austria, p. 65-66.

97. DINKA, M. \& BERCZIK, Á. (1994): Ecotone studies in the Lake Fertö/Neusiedlersee Biosphere Reserve. International Workshop on Ecology and Management of Aquatic-Terrestrial Ecotones, Seattle, USA, Proecedings, p. 48-58.

98. LÁNG, I., BANCZEROWSKI, J. \& BERCZIK, Á. (Eds.) (1994): Annotált Bibliográfia. A Bös (Gabčikovo) Nagymarosi Vizlépcsörendszer hatásterületét érintö fontosabb környezeti kutatásokról. MTA Budapest, 250 pp.

99. LÁNG, I., BANCZEROWSKI, J. \& BERCZIK, Á. (Eds.) (1994): Annotated References to the Bös (Gabčikovo)-Nagymaros Danube Barrage System Project. MTA Budapest, 277 pp.

1995

100. BERCZIK, Á. (1995): Die Entstehung und Entfaltung der Donauforschung in Ungarn. Opuscula Zoologica (Budapest), 27/28: 117-122.

101. BERCZIK, Á. (1995): A folyómenti ökoszisztémák szerepe a biodiverzitás szempontjából. In. SZARVAS G. \& KÖNCZEY R. (Eds.) Élővízfolyosók Magyarországon (1993-1994). Háttértanulmány. IUCN Budapest, p. 8-11.
1997

102. BERCZIK, Á. (1997): Changes of the hydrobiological conditions in 1993-1994. In. Láng, I., BANCZEROWSKI, I. \& BERCZIK, Á. (Eds.) Studies on the environmental state of the Szigetköz after the diversion of the Danube, MTA Szigetköz Bizottság, Budapest, p. 55-60.

103. BERCZIK, Á. \& NOSEK, J. (1997): Gerinctelen állatok kutatása a Balatonon. In. SALÁNKI J. (Ed.) A Balatonkutatás eredményei 1981-1996, VEAB Veszprém, p. 137-194.

104. TAKÁTS, T., BERCZIK, Á. \& DinKA, M. (1997): The effect of hydrological and meteorological conditions on the water chemistry of a shallow lake. Verhandlungen des Internationalen Verein Limnologie, 26: 392-396.

1998

105. BERCZIK, Á. (1998): Hydrobiological effects of a lowland river barrage system on the Danube. Verhandlungen des Internationalen Verein Limnologie, 26: 975-977.

1999

106. BERCZIK, Á. (1999): Eröffnungsrede des Tagungspräsidenten. 31. Konferenz der IAD, Baja, Ungarn, 1996, Limnologische Berichte Donau II, p. 3-8.

2001

107. BERCZIK, Á. (2001): Limnológia a Magyar Hidrológiai Társaságban. Hidrológiai Közlöny, 81: 283 .

108. KISS, A. \& BERCZIK, Á. (2001): A hansági Fehér-tó hidrobiológiai jellege és Cladocera, Ostracoda, Copepoda együttesei. In. BORHIDI, \& A. BotTA-DukÁt, Z. (Eds.) Ökológia az ezredfordulón II., MTA Budapest, 127-145.

109. VARGA, I. \& BERCZIK, Á. (2001): Macroinvertebrate communities in reed litter. Verhandlungen des Internationalen Verein Limnologie, 27: 3566-3569.

110. VÖRÖs, L., V. BALOGH, K., KonCZ, E., BerCZIK, Á., DinKA, M., KISS, A., VARGA, I. \& OLDAL, I. (2001): Hazai tavak és víztározók ökológiai állapotának felmérése: Marcali-víztározó. In. BORHIDI, A. \& BOTTA-DUKÁT, Z. (Eds.) Ökológia az ezredfordulón III., MTA Budapest, p. 221-238. 
2002

111. BERCZIK, Á. (2002): IV. A Magyar Dunakutató Állomás tevékenysége. 1. Dunakutatás. In. FEKETE, G., KISS, K.T., KOVÁCSNÉ LÁNG, E., Kun, A., NoseK, J. \& RÉvész, A. (Eds.) Az MTA Ökológiai és Botanikai Kuttató Intézet 50 éve (1952-2002), Vácrátót, p. 285-296.

112. BERCZIK, Á. (2002): IV. A Magyar Dunakutató Állomás tevékenysége. 3. Az MDÁ kutatómunkáját segitö kapcsolatok. In. FEKETE, G., KISS, K.T., KovÁCSNÉ LÁNG, E., Kun, A., NoSEK, J. \& RÉVÉSZ, A. (Eds.) Az MTA Ökológiai és Botanikai Kuttató Intézet 50 éve (1952-2002), Vácrátót, p. 305-306.

113. BERCZIK, Á. (2002): IV. A Magyar Dunakutató Állomás tevékenysége. 4. Az MTA Magyar Dunakutató Állomás további feladatai. In. FEKETE, G., KISS, K.T., KovÁCSNÉ LÁNG, E., Kun, A., NoseK, J. \& RÉvÉsz, A. (Eds.) Az MTA Ökológiai és Botanikai Kuttató Intézet 50 éve (1952-2002), Vácrátót, p. 306-311.

114. DinKA, M., BERCZIK, Á., SzABÓ, E. \& VARGA, I. (2002): A nádasállomány szerkezete, vízkémiai jellemzői és az aratás hatásai a Fertön. In. FEKETE, G., KISS, K.T., KovÁCSNÉ LÁNG, E., Kun, A., NoseK, J. \& RÉvÉSz, A. (Eds.) Az MTA Ökológiai és Botanikai Kutató Intézet 50 éve (1952-2002), Vácrátót, p. 393-410.

115. Dévai, Gy., BercziK, Á., Bíró, P., Gallé, L., GulyÁs, P. \& BANCSI, I. (2002): A Magyar Tudományos Akadémia Biológiai Tudományok Osztálya Tiszai Tudományos Bizottságának helyzetelemzése és állásfoglalása. Acta biologica Debrecina. Supplementum oecologica Hungarica, 11(2): 11-22.

116. KISS, A., SchÖLl, K. \& BERCZIK, Á. (2002): A hansági Fehér-tó Cladocera, Copepoda és Rotatoria együtteseinek rövid értékelése. In. FEKeTE, G., Kiss, K.T., Kovácsné LÁng, E., Kun, A., NoseK, J. \& RÉVÉsz, A. (Eds.) Az MTA Ökológiai és Botanikai Kuttató Intézet 50 éve (1952-2002), Vácrátót, p. 411-416.

\section{3}

117. BERCZIK, Á. (2003): Miért van szükség a gemenci vizek hidrobiológiai vizsgálatára? In. SoMOGYVÁRI, O. (Ed.) Élet a Duna-ártéren természetvédelemről sokszemközt címü tudományos tanácskozás összefoglaló kötete, Duna-Dráva Nemzeti Park Igazgatóság \& Bajai
Ifjúsági Természetvédelmi Egyesület, Pécs, p. 7-10.

118. BERCZIK, Á. (2003): The major features of János Balogh's life work. Acta Zoologica Academiae Scientiarum Hungaricae, 49: 323-325.

119. BERCZIK, Á. \& VARGA, Z. (2003): Vizi élöhelyek. In. LÁNG. I., BEDÖ, Z. \& CSETE, L. (Eds.) Növény, állat, élőhely. Magyar Tudománytár 3. MTA Társadalomkutató Központ, Kossuth Kiadó, Budapest, p. 205-223.

120. RÁth, B., Janauer, G., PAll, K. \& BercziK, Á. (2003): The aquatic macrophyte vegetation in the Old Danube/Hungarian bank, and other water bodies of the Szigetköz wetlands. Archiv für Hydrobiologie, Supplement 147(1-2), Large Rivers, 14(1-2): 129-142. doi: $10.1127 / 1 \mathrm{r} / 14 / 2003 / 129$

2004

121. Dinka, M., Ágoston-Szabó, E. \& BercziK, Á., KutruCZ, Gy. (2004): Influence of water level fluctuation on spatial dynamic of the water chemistry at Lake Fertö/Neusiedler See. Limnologica, 34 (1-2): 48-56. doi: $10.1016 /$ S0075-9511(04)80021-5

2005

122. BERCZIK, Á. \& GUTI, G. (2005): A Szigetköz ökológiai vízigényének meghatározása, különös tekintettel a szlovák-magyar tárgyalások folytatására (Tájékoztató a Miniszterelnöki Hivatal Területfejlesztési Hivatalának megbízásából készült tanulmányról). In. VINKLER P. (Ed.) Tudomány, Innováció, Életminőség. Az MTA intézetei az ország gyarapodásáért. MTA Ökológiai és Botanikai Kutató Intézet, Budapest, p. 62-63.

123. BERCZIK, Á. \& GuTI, G. (2005): A Szigetköz ökológiai vízigényének meghatározása, különös tekintettel a szlovák-magyar tárgyalások folytatására. In. TÖRÖK, K. \& KOVÁCSNÉ LÁNG, E. (Eds.) Válogatás az MTA ÖBKI kutatási eredményeiből, Vácrátót, p. 33-36.

124. DINKA, M. \& BERCZIK, Á. (2005): Néhány vízkémiai paraméter különbözösége a gemenci mellékágakban. In. TAMÁSI, E.A. (Ed.) Élet a Duna-ártéren - ember a természetben. Bajai Ifjúsági Természetvédelmi Egyesület, Baja, p. 58-67. 


\section{6}

125. BERCZIK, Á. (2006): Felelösségünk a Fertö jövőjéért az európai értékrend tükrében. A Fertő-tó jelene és jövője Konferencia, Sopron, 2005. szeptember 22. Debreceni Egyetem TTK, Környezetgazdálkodási és Környezetpolitikai Központ, p. 1-22.

126. BERCZIK, Á. \& BuZETZKY, Gy. (2006): Realistic rehabilitation of the Gemenc region of the Danubian floodplain based on modern ecological priorities. Verhandlungen des Internationalen Verein Limnologie, 29: 1595-1599.

127. BERCZIK, Á. \& GUTI, G. (2006): Ecological water requirements of the Szigetköz floodplain (Middle Danube). In. TÖRÖK, K. \& LÁNG KOVÁCS, E. (Eds.) Recent research results supporting sustainability. Institute of Ecology and Botany, HAS, Vácrátót, p. 33-35.

128. Janauer, G.A., Filzmoser, P., Otahelova, H., GabersčIK, A., TOPIC, J., BERCZIK, Á., IgIC, R., Vulchev, V., SARbu, A., Kohler, A. \& EXLER, N. (2006): Macrophyte Habitat Preference, River Restoration, and the WFD: making use of the MIDCC data base. Proceedings, $36^{\text {th }}$ International Conference of IAD. Austrian Committee Danube Research/ IAD Vienna, p. 81-85.

129. SchÖLl, K., DinKA, M., BERCZIK, Á., KISS, A., ÁGOSTON-SZABÓ, E., SCHMIDT, A., FEHÉr, G. (2006): Hydrobiological differences in the Danubian water system with periodically connections with the Danube (Gemenc floodplain, Danube-Drava National Park, Hungary). Proceedings $36^{\text {th }}$ International Conference of IAD. Austrian Committee Danube Research/IAD Vienna, p. 338-342.

\section{7}

130. BERCZIK, Á. (2007): Az MTA Magyar Dunakutató Állomása (Elözmények - létesités kutatástörténet). In. Nosek, J. \& OERTEL, N. (Eds.) „A Dunának, mely múlt, jelen s jövendö...", 50 éves az MTA Magyar Dunakutató Állomása (1957-2007), MTA Ökológiai és Botanikai Kutató Intézet - Magyar Dunakutató Állomás, Göd - Vácrátót, p. 11-20.

131. Dinka, M., Ágoston-Szabó, E., BercziK, Á. \& KuTRUCZ, Gy. (2007): Vízjárás hatása a vízkémiai paraméterek térbeli alakulására a Fertőn. Hidrológiai Közlöny, 87/1: 28-34.
132. DinKA, M., BERCZIK, Á., ÁGOSTON L., ScHÖLL, K., KISS, A. \& GUTI, G. (2007): Kutatások a Fertö-Hanság területén. Fertő. In. Nosek, J. \& OERTEL, N. (Eds.) „A Dunának, mely múlt, jelen s jövendő...", 50 éves az MTA Magyar Dunakutató Állomása (1957-2007), MTA Ökológiai és Botanikai Kutató Intézet Magyar Dunakutató Állomás, Göd - Vácrátót, p. 124-139.

133. KISS, A., BERCZIK, Á., DinKA, M., SchÖlL, K., ÁGoston L., GuTI, G. \& PUKY, M. (2007): Kutatások a Fertö-Hanság területén. Hanság. In. Nosek, J. \& OERTEL, N. (Eds.) „A Dunának, mely múlt, jelen s jövendő...”, 50 éves az MTA Magyar Dunakutató Állomása (1957-2007), MTA Ökológiai és Botanikai Kutató Intézet Magyar Dunakutató Állomás, Göd - Vácrátót, p. $140-145$.

2008

134. BERCZIK, Á. (2008): The Hungarian Danube Research Station of the Hungarian Academy of Sciences (Background - Establishment Research history) 1957-2007. Proceedings of the 37th IAD Conference, Chisinau/Moldova, p. 8-21.

2009

135. DINKA, M. \& BERCZIK, Á. (2009): Az MTA Magyar Dunakutató Állomás fertöi hidrobiológiai kutatásainak áttekintése 1972-től. In. LAKATOS, F. \& KUI, B. (Eds.) Nyugat-magyarországi Egyetem, Erdömérnöki Kar, Kari Tudományos Konferencia Kiadvány, NymE Kiadó Sopron, p. 24-27.

136. Dinka, M., Ágoston-Szabó, E., KIss, A., SCHÖLL, K. \& BERCZIK, Á. (2009): A biodiverzitás különleges esete: a Fertö vizterének mozaikossága. In. LAKATOS, F. \& KUI, B. (Eds.) Nyugat-magyarországi Egyetem, Erdőmérnöki Kar, Kari Tudományos Konferencia Kiadvány, NymE Kiadó Sopron, p. 200-203.

137. DinKA, M., SCHÖll, K., KISS, A., ÁGOSTON-SZABÓ, E. \& BERCZIK, Á. (2009): A Nyirkai-Hany és a Keleti Mór-rétek (Fertö-Hanság Nemzeti Park) restaurácios folyamatanak hidrobiológiai vizsgálata. In. TÖRÖK, K., KISS, K.T \&, KERTÉSz, M. (Eds.) Válogatás az MTA ÖBKI kutatási eredményeiből, 2009. ÖBKI Mühelyfüzetek 2, p. 129-137. 
138. SchÖLl, K., DinKA, M., KISS, A., ÁGOSTON-SzABÓ, E. \& BERCZIK, Á. (2009): A Duna vizjárasának hidrobiologiai hatásai a Duna gemenci hullámterenek mellekágaiban. In. TÖRÖK, K., KISS, K.T \&, KERTÉSZ, M. (Eds.) Válogatás az MTA ÖBKI kutatási eredményeiből, 2009. ÖBKI Mühelyfüzetek 2, p. 105-113.

139. SchÖll, K., KISS, A., DinKA, M., ÁGOSTON-SZABÓ, E., SCHMIDT, A., FEHÉR, G. \& BERCZIK, Á. (2009): A gemenci hullámtér víztereinek hidrobiológiai különbségei (Duna-Dráva Nemzeti Park). Magyar Hidrológiai Társaság XXVII. Országos Vándorgyülés, Baja, 2009. július 1-3. p. 1-11.

2010

140. Ágoston-Szabó, E., Dinka, M., SchÖLl, K., KISS, A. \& BERCZIK, Á. (2010): Leaching losses with special references on nutrient dynamics from five leaf litter species in a side arm of the Danube at Gemenc floodplain, Hungary. $38^{\text {th }}$ IAD Conference Dresden, booklet 1, p. 1-6.

141. Ágoston-SzabÓ, E., DinKA, M., SchÖLl, K., KISS, A. \& BERCZIK, Á. (2010): A vízkémiai jellemzök és a zooplankton együtesek tér-és időbeli eltérései a Külsö-Béda holtágban. In. TAMÁs E.A. (Ed.) Élet a Duna árterén. Bajai Ifjúsági Természetvédelmi Egyesület, Baja, p. $11-18$.

142. DinKA, M., SchÖll, K., ÁGOSTON-SZABÓ, E., KISS, A. \& BERCZIK, Á. (2010): Water chemical characteristics and the spatio-temporal patterns of zooplankton assemblages in a side arm of the Danube (1437-1440 rkm, Hungary). 38 ${ }^{\text {th }}$ IAD Conference Dresden, booklet 2, p. 1-6.

143. KISS, A., SCHÖLl, K., DINKA, M., ÁGOSTON-SZABÓ, E. \& BERCZIK, Á. (2010): Spatial differences of the zooplankton assemblages and chemical characteristics of water in a plesiopotamal side-arm of the Gemenc Floodplain Area (Duna-Dráva National Park, Hungary). $38^{\text {th }}$ IAD Conference Dresden, booklet 3, p. 1-6.

144. SchÖLl, K., KISS, A., DinKA, M., ÁGOSTON-SZABÓ, E. \& BERCZIK, Á. (2010): Spatiotemporal patterns of zooplankton densities according to water chemical caracteristics and hydrological events in a river-floodplain system
(Duna-Dráva National Park, Hungary). $38^{\text {th }}$ IAD Conference Dresden, booklet 4, p. 1-6.

\section{1}

145. BERCZIK, Á. (2011): A Duna-kutatás akadémiai bázisának kialakitásáról. In. LÁNG, I. (Ed.) Akadémia, a nemzet tanácsadója. Tanulmánykötet Glatz Ferenc 70. születésnapjára. MTA Társadalomkutató Központ, Budapest, p. 1067-1074.

2012

146. ÁGoston-Szabó E., DinKA, M., SchÖLl, K., KISS, A. \& BERCZIK, Á., (2012): Linking sediment mineralization processes with nutrient dynamics of a Danube oxbow (Gemenc, Hungary). IAD Limnological reports 39. Göd Vácrátót, Hungary, p. 133-139.

147. DózSA-FARKAS, K., CsUZDI, Cs. \& BERCZIK Á. (2012): In Memoriam Prof. István Andrássy (1927-2012). Opuscula Zoologica (Budapest), 43(2): 109-120.

148. KISS, A., SCHÖLL, K., DinKA, M. \& BERCZIK, Á. (2012): Zooplankton monitoring in the Szigetköz floodplain of the Danube (Hungary) (1999-2011): long term results and consequences. IAD Limnological reports 39. Göd - Vácrátót, Hungary, p. 195-201.

149. SCHÖLL, K., KISS, A., DINKA, M. \& BERCZIK, Á. (2012): Mid-term changes of planktonic rotifer communities in the Szigetköz floodplain of the Danube, Hungary (2003-2011). IAD Limnological reports 39. Göd - Vácrátót, Hungary, p. 179-185.

150. SCHÖLL, K., KISS, A., DinKA, M. \& BERCZIK, Á. (2012): Flood-pulse effects on zooplankton assemblages in a river-floodplain system (Gemenc floodplain of the Danube, Hungary). International Review of Hydrobiology, 97(1): 41-54. doi: 10.1002/iroh.201111427

2014

151. Ágoston-Szabó, E., SchÖll, K., KISs, A., BERCZIK, Á. \& DinKA, M. (2014): Decomposition of Willow Leaf Litter in an Oxbow Lake of the Danube River at Gemenc, Hungary. Acta Zoologica Bulgarica, Supplement 7: 197-202.

152. KISS A., ÁgOston-Szabó E., DinKA M., SCHÖLL K. \& BERCZIK Á. (2014): Microcrustacean (Cladocera, Copepoda, Ostracoda) 
diversity in three side arms in the Gemenc Floodplain (Danube River, Hungary) in different hydrological situations. Acta Zoologica Bulgarica, Supplement 7: 135-141.

153. KalcheV, R., Dinka, M., BeshKova, M., KalCHEVA H., BERCZIK, Á. \& ÁGOSTON-SzABÓ, E. (2014): Factors Influencing the Chemical Characteristics and Nutrient Retention/Release Potential of Wetlands in the Middle (Hungarian) and Lower (Bulgarian) Danube River. Acta Zoologica Bulgarica, Supplement 7: 75-81.

154. TARJÁNYi N. \& BERCZIK, Á. (2014) Spatial distribution of phytophilous macroinvertebrates in a side arm of the middle Danube river. Acta Zoologica Bulgarica Supplement 7: 13-17.

\section{5}

155. DinkA M., KISS A., MAgYAR N. \& ÁgostonSzabó, E. (2016). Effects of the introduction of pre-treated wastewater in a shallow lake reed stand. Open Geosciences, 8(8): 62-77. doi: $10.1515 /$ geo-2016-0008

156. Kiss A., Ágoston-Szabó E., Dinka M. \& BERCZIK, Á. (2015): Microcrustacean diversity in the Gemenc - Béda - Karapancsa Floodplains (Danube-Drava National Park), Hungary): rare and alien species. Opuscula Zoologica (Budapest), 46:183-197. doi: 10.18348/opzool.2015.2.183

\section{6}

157. KalcheV, R., BercziK, Á., BeshKova, M., DinKa, M., Kalcheva, H., Kiss, A. \& ÁgosTON-SZABÓ, E. (2016): Trophic status and phytoplankton limitation conditions in selected Bulgarian and Hungarian Danube River wetlands. Transylvanian Review of Systematical and Ecological Research, 18(2): 19-28. doi: $\underline{10.1515 / \text { trser-2015-0084 }}$

158. Kalcheva, H., Dinka, M., Ágoston-SzabÓ, E., BERCZIK, Á., KALCHEV, R., TARJÁNYI, N. \& KISS, A. (2016): Bacterioplankton from two Hungarian Danube River wetlands (BédaKarapancsa, Danube-Drava National Park) and its relations to environmental variables. Transylvanian Review of Systematical and Ecological Research, 18(1): 1-12. doi: $10.1515 /$ trser-2015-0075

\section{Some further activities of Professor Berczik}

Upon an international cooperation request organizing the long term hydrobiological research of the $417 \mathrm{~km}$ long Hungarian part of the Danube, then leading it according the concept of professor Endre Dudich (Eötvös Loránd University, Budapest) under the auspices of the Hungarian Danube Research Institute. Establishing an international cooperation among the research centres of $10 \mathrm{Da}-$ nubian countries during 30 years, starting in 1957.

He was leading the hydrobiological monitoring of the influenced area of the barrage system in Bös (Gabcikovo) along the Hungarian-Czechoslovak part of the Danube with the participation of 15 researchers from 1991 to 2016. (a report of 4500 pages). Considering the intentions of the HAS he compiled the written documents of the Hague international legal process. He continuously participated in this kind of work done by state institutions - occasionally as a government representative - during 15 years. For four years he was the Hungarian chairman of the joint committee of the Hungarian and Slovak Academy of Sciences.

In a German and Hungarian cooperation, with the help of a subsidy granted by DBU (Deutsche Bundesstiftung Umwelt) he was leading the investigation of the river - flood plain hydrobiological interactions on the territory of Gemenc along the Hungarian Danube with 12 Hungarian researchers between 2005 and 2010. (38 publications, a report of 260 pages). The German partner institute was WWF Aueninstitut, Rastatt. The director, Dr. Prof. Emil Dister was the leader of the whole project and also that of the German project part.

The 10 year long biological and chemical examination of the Danube bank filtered drinking water well-field and ground water enrichment basins of the Budapest Waterworks. Leading the work between 1957 and 1967, involving 6 researchers. A report of 700 pages was made and experts' opinions were given. 
Based on an agreement between the Hungarian and the Austrian Academy of Sciences the first Hungarian organized hydrobiological research of Lake Fertö /Neusiedler. The elaboration of the concept and partly also the leading of the research was Berczik's task. However, a significant part of the research work and its coordination were done by assistant professor Mária Dinka. In the period between 1972 and 2016, 191 academic articles were published by 63 authors. 